\title{
Avaliação da presença de microrganismos isolados da superfície do diafragma de estetoscópios usados por alunos do curso de medicina
}

\author{
Evaluating isolated microorganisms present on the surface of stethoscope's \\ diaphragm used by medical students
}

\author{
Lyza Alencar Siqueira ${ }^{1}$, Liliane Silva Anjos ${ }^{1}$, Thainá Pereira do Nascimento ${ }^{1}$, \\ Valeska Balen Ronsoni ${ }^{1}$, Marilene Rivany Nunes ${ }^{2}$, Bethânia Cristhine de Araújo ${ }^{3}$
}

Siqueira LA, Anjos LS, Nascimento TP, Ronsoni VB, Nunes MR., Araújo MBC. Avaliação da presença de microrganismos isolados da
superfície do diafragama de estetoscópios usados por alunos do curso de Medicina do UNIPAM / Evaluating isolated microorganisms
present on the surface of stethoscope's diaphragm used by medical students. Rev Med (São Paulo). 2020 maio-jun.;99(3):242-5.

RESUMO: As infecções associadas aos cuidados de saúde (IACS) representam no Brasil um problema que requer cuidado, estando entre as seis primeiras causas de óbito no país, de modo que a referida causa está fortemente ligada ao desequilíbrio da microbiota e da imunidade do hospedeiro. Dentre os instrumentos que podem contribuir com o aparecimento das IACS, destacam-se os dispositivos médicos, como o estetoscópio, que pode ser um importante vetor de infecção cruzada, caso não seja higienizado corretamente. O objetivo desse trabalho foi identificar a presença de agentes biológicos bacterianos contidos nos diafragmas dos estetoscópios de alunos do curso de Medicina do Centro Universitário de Patos de Minas (UNIPAM). Realizou-se um estudo observacional, transversal e descritivo através da coleta de material microbiológico de 52 estetoscópios. As amostras foram coletadas com swabs estéreis, friccionados na superfície do diafragma de estetoscópios e depois foram repicadas em caldo BHI (Brain Heart Infusion), ágar padrão para contagem (PCA), ágar Sal Manitol (SM) e ágar eosina azul de metileno (EMB). Para a caracterização das culturas foram utilizados técnicas de identificação bacteriana por inoculação e série bioquímica tradicional, após isso foi realizada a coloração Gram e as características morfo-tintoriais foram analisadas. Dos diafragmas de estetoscópios avaliados, $50 \%(n=26)$ apresentaram contaminação com crescimento positivo para pelo menos um dos microrganismos pesquisados: enterobactérias, bactérias totais, Staphylococcus aureus e bacilos entéricos gram negativos. Os resultados permitem observar que as bactérias Gram-negativas prevaleceram nos estetoscópios amostrados, as quais são importantes agentes patogênicos. Nesse sentido, pode-se concluir que a prática de higienização do diafragma dos estetoscópios deve ser melhor difundida nas instituições de ensino por veicular doenças e colocar em risco a saúde do paciente.

Descritores: Estetoscópios; Contaminação biológica; Fenômenos microbiológicos; Bactérias; Estudantes de medicina.

\begin{abstract}
Infections associated with healthcare (IACS) represent a problem in Brazil that requires care, being among the first six causes of death in the country, so that this cause is strongly linked to the imbalance of the microbiota and the host's immunity. Among the instruments that can contribute to the appearance of HAIs, medical devices, such as the stethoscope, can be an important vector of crossinfection, if not properly sanitized. The objective of this work was to identify the presence of bacterial biological agents contained in the diaphragms of stethoscopes of students of the Medicine course at the University Center of Patos de Minas (UNIPAM). An observational, cross-sectional and descriptive study was carried out by collecting microbiological material from 52 stethoscopes. The samples were collected with sterile swabs, rubbed on the diaphragm surface of stethoscopes and then they were transferred in BHI broth (Brain Heart Infusion), standard count agar (PCA), Salt Mannitol agar (SM) and methylene blue eosin agar (EMB). For the characterization of cultures, techniques of bacterial identification by inoculation and traditional biochemical series were used, after that Gram staining was performed and the morpho-dye characteristics were analyzed. Of the diaphragms of stethoscopes evaluated, $50 \%(\mathrm{n}=26)$ showed contamination with positive growth for at least one of the surveyed microorganisms: enterobacteria, total bacteria, Staphylococcus aureus and enteric gram-negative bacilli. The results show that Gram-negative bacteria prevailed in the sampled stethoscopes, which are important pathogens. In this sense, it can be concluded that the practice of cleaning the diaphragm of stethoscopes should be better disseminated in educational institutions for spreading diseases and putting the patient's health at risk.
\end{abstract}

Keywords: Stethoscopes; Biological contamination; Microbiological Phenomena; Microorganisms; Bacteria; Students, medical.

Trabalho realizado no Centro Universitário de Patos de Minas (UNIPAM), Patos de Minas, MG.

1. Acadêmico de medicina do Centro Universitário de Patos de Minas (UNIPAM), Patos de Minas, MG. Siqueira LA - https://orcid.org/0000-0001-9724-1289, Anjos LS - https://orcid.org/0000-0001-9763-9166, Nascimento TP - https://orcid.org/0000-0003-0784-2991, Ronsoni VB -https://orcid.org/0000-0001-87923139. Email: lyzaalencar@gmail.com, lilianesanjos@outlook.com, tnaperreira@hotmail.com, valeskaronsoni@outlook.com.

2.Enfermeira Doutora em Enfermagem em Saúde Pública pela EERP-USP; Docente do Curso de Enfermagem e Medicina do Centro Universitário de Patos de Minas - UNIPAM. https://orcid.org/0000-0003-4958-2366. Email: maryrivany@unipam.edu.br.

3. Bióloga pela Centro Universitário de Patos de Minas (UNIPAM), Mestre em genética e bioquímica pela UFU, Professora da UNIPAM. https://orcid.org/00000002-1496-0390. Email: bethania@unipam.edu.br.

Endereço para correspondência: Lyza Alencar Siqueira. Rua Major Gote, 944 apto 701 - Alto dos Caiçaras, Patos de Minas, MG, Brasil. CEP: $38702-054$. Email: lyzaalencar@gmail.com. 


\section{INTRODUÇÃO}

A infecções associadas aos cuidados de saúde (IACS) representam no Brasil um problema que requer cuidado, estando entre as seis primeiras causas de óbito no país, de modo que a referida causa está fortemente ligada ao desequilíbrio da microbiota e da imunidade do hospedeiro ${ }^{1}$.

Dentre os instrumentos que podem contribuir com o aparecimento das IACS, destacam-se os dispositivos médicos, como o estetoscópio, que pode ser um importante vetor de infecção cruzada, caso não seja higienizado corretamente. Junto a isso, o que aumenta a importância do seu cuidado primário de limpeza e desinfecção é o fato de ele ser usado habitualmente por médicos e enfermeiros, e por isso, entra em contato direto com vários pacientes.

Sabe-se que o conhecimento a respeito dos cuidados para com o estetoscópio é pouco difundido no meio da saúde. Devido ao baixo número de pesquisas relacionadas ao tema, mais estudos são necessários para determinar as características epidemiológicas de microrganismos de importância clínica para o serviço de saúde, já que o perfil das infecções varia entre as instituições, quando presentes nas superfícies, soluções, equipamentos e possível semelhança com resultados positivos de culturas dos pacientes ${ }^{2}$. Um contato de mão única com uma superfície contaminada resulta num grau variável de transferência de patógenos ${ }^{2}$. Mãos contaminadas também podem ser a fonte de re-contaminação da superfície ${ }^{2}$.

As bactérias conseguem atacar o organismo humano, seja através da produção de endotoxinas (lipopolissacarídeo - LSP) ou pela produção de exotoxinas (proteínas). O primeiro grupo de toxinas, em baixas concentrações no corpo humano gera reações de alarme (ex: febre), enquanto em altas concentrações causa choque e morte. Já as exotoxinas são responsáveis por ações no sistema nervoso, perda de fluído ao nível intestinal, inibição da síntese proteica e lise de células ${ }^{3}$.

As exotoxinas geralmente são produzidas pelas bactérias Gram-positivas, seu efeito no organismo é específico para uma estrutura ou função celular afetada, são instáveis ao calor (podem ser destruídas em 60 a 80 ${ }^{\circ} \mathrm{C}$ ), possuem elevada toxicidade (capacidade de produzir doença), não costumam gerar febre, são neutralizadas por antitoxinas e possuem dose letal baixa. As endotoxinas, por sua vez, têm produção principalmente pelas Gramnegativas, possuindo efeitos gerais no organismo (febre, fraqueza, dores e choque), são estáveis ao calor, suportando autoclave $\left(121^{\circ} \mathrm{C}\right.$ por uma hora), têm baixa toxicidade, não são facilmente neutralizadas por antitoxinas e possuem dose letal consideravelmente alta ${ }^{3}$.

Ao analisar a prevalência de contaminação bacteriana em estetoscópios, Dutra et al. ${ }^{4}$ afirma ter encontrado $96,2 \%$ dos instrumentos analisados contaminados, sendo que houve prevalência de S. aureus (78\%), seguido de Corynebacterium spp. (26\%). Concernente aos organismos Gram-negativos foram encontrados 17,3\% de Acinetobacter spp. O autor salienta que esse último grupo de microrganismos (Gram-negativos) são causadores de infecções potencialmente graves, visto que costumam causar contaminação do trato urinário, trato gastrointestinal, trato respiratório, podendo até chegar a quadro de septicemia, além de oferecerem elevada resistência a múltiplas drogas ${ }^{4}$.

No que diz respeito ao estudo de $\mathrm{Neves}^{5}$, que realizou uma análise bacteriológica de 40 jalecos, não foi observado crescimento de bactérias Gram-negativas, havendo prevalência de Bacillus spp. (38\%), Staphylococcus spp. (20\%) e Streptococcus spp. (42\%).

No estudo "Quantitativo microbiano em jalecos de estudantes da área da saúde em instituição de ensino superior", encontrou uma maior colonização por Staphylococcus Gram-positivos (68\%), seguidos dos Cocos Gram-positivos (16,8\%) e Bacilos Gram-negativos $(5,2 \%)^{6}$.

Por fim, na pesquisa realizada por Sales et al. ${ }^{2}$ observou-se a presença de bactérias nas superfícies inanimadas de uma unidade de terapia intensiva, onde foi encontrado uma maior prevalência de germe Gramnegativo, mais especificamente Acinetobacter baumannii multirresistente, que está relacionada com a ocorrência de pneumonia nosocomial.

Diante das evidências encontradas nos estudos mencionados é possível estabelecer relação com o que é relatado na literatura ${ }^{3}$, visto que pesquisas mostram uma maior prevalência de bactérias Gram-positivas em infecções humanas, a qual possui alta toxicidade. Por outro lado, apesar do menor número das Gram-negativas associadas às infecções, percebe-se que mesmo com baixa toxicidade, elas apresentam maior resistência às antitoxinas $^{2}$.

Portanto, identifica-se a relevância deste trabalho em reconhecer a presença de microoganismos isolados no diafragma de estetoscópios, visto que quando não se realiza a correta higienização de um material que entra em contato com diversos pacientes, estes acabam tornando-se portadores de uma importante via de infecção cruzada e potencial causadora das IACS.

Com efeito, espera-se que os resultados obtidos no presente estudo auxiliem na conscientização da importância de se realizar a correta limpeza dos estetoscópios e na disseminação dessa prática. Para tanto, o presente trabalho tem como objetivo identificar a presença de agentes biológicos bacterianos sob a superfície do diafragma de estetoscópios, usados por alunos do curso de Medicina, do Centro Universitário de Patos de Minas (UNIPAM).

\section{MÉTODOS}

Trata-se de um estudo observacional, transversal, analítico e quantitativo feito através da coleta de 
material microbiológico do diafragma de estetoscópios disponibilizados voluntariamente pelos alunos do terceiro ao sexto ano do curso de Medicina do UNIPAM. Esses possuem como local de contato as unidades básicas de saúde (UBS), unidade de pronto atendimento (UPA) e, principalmente, hospital de alta complexidade/ referência, todos localizados em Patos de Minas/ MG. As análises foram realizadas no laboratório de Microbiologia Geral do UNIPAM, bloco D, $1^{\circ}$ piso, sala 105.

As amostras foram coletadas através de swabs estéreis, friccionados no diafragma dos estetoscópios, colocados em solução salina e transportadas ao laboratório de microbiologia. Posteriormente as amostras foram inoculadas em caldo BHI (Brain Heart Infusion) incubadas por 24 horas em estufa de aerobiose à $35^{\circ} \mathrm{C} \pm 1$. Após este período de incubação, as amostras foram repicadas para ágar padrão para contagem (PCA), ágar Sal Manitol (SM) e ágar eosina azul de metileno (EMB), incubadas por 2448 horas, em aerobiose à $35^{\circ} \pm 1^{\circ} \mathrm{C}$ e realizadas as provas bioquímicas para a identificação bacteriana ${ }^{7,8}$.

Para identificação de Staphylococcus aureus, foram utilizadas as provas de fermentação do manitol, catalase e coagulase. Para identificação de bactérias totais foram realizadas coloração de gram para classificar bactérias com base na morfologia celular, arranjo e afinidade por corantes, conforme a composição química de sua parede celular, prova de catalase e coagulase. Para identificar os bastonetes Gram negativos, foram utilizados prova de oxidaçãofermentação da glicose, IAL, citrato de Simmons, caldo arginina, lisina e ornitina descarboxilase e motilidade ${ }^{7,8}$.

O período de amostragem ocorreu entre fevereiro e abril do ano de 2018. A análise dos dados foi feita de forma explicativa, apresentados em forma de tabelas.

\section{RESULTADOS}

Foram avaliados 52 diafragmas de estetoscópios dos alunos do curso de Medicina do Centro Universitário de Patos de Minas, sendo que 26 (50\%) apresentaram contaminação. Dessas, nenhuma apresentou crescimento no meio EMB, apenas no meio PCA e SM.

Para análise das características morfo-tintoriais utilizou-se a técnica de coloração Gram, para caracterizar as bactérias com crescimento positivo em ágar PCA, e essa apresentou os seguintes resultados: 6 lâminas com crescimento de Cocos Gram negativos e positivos; 7 lâminas com crescimento de Cocos Gram negativos; 6 lâminas com crescimento de Cocos Gram positivos; 3 lâminas com crescimento de Bacilos Gram positivos e 4 lâminas com crescimento de Bacilos Gram negativos. Os dados em comento estão representados na Tabela 1.

Dentre os estetoscópios contaminados, $65 \%$ $(\mathrm{n}=17)$ apresentaram bactérias Gram negativas, enquanto $35 \%(n=9)$ apresentaram Gram positivas. Em relação às características morfológicas, $73 \%(\mathrm{n}=19)$ eram do tipo cocos e $27 \%(n=7)$ do tipo bacilos.
Tabela 1: Características morfo-tintoriais das bactérias encontradas

\begin{tabular}{ll}
\hline $\begin{array}{l}\text { Número estetoscópios } \\
\text { contaminados }\end{array}$ & $\begin{array}{l}\text { Características morfo- } \\
\text { tintoriais }\end{array}$ \\
\hline 6 & Cocos Gram - e + \\
\hline 7 & Cocos Gram - \\
\hline 6 & Cocos Gram + \\
\hline 3 & Bacilo Gram + \\
\hline 4 & Bacilo Gram - \\
\hline Total: 26 & \\
\hline
\end{tabular}

Fonte: Dados da pesquisa, 2018.

Em duas amostras houve crescimento de mais de uma espécie bacteriana. Foram isoladas (54\%) de Staphylococcus sp coagulase negativa, (23\%) cepas de Klebsiella sp e (7,6\%) de Staphylococcus aureus nos diafragmas amostrados (Figura 1).

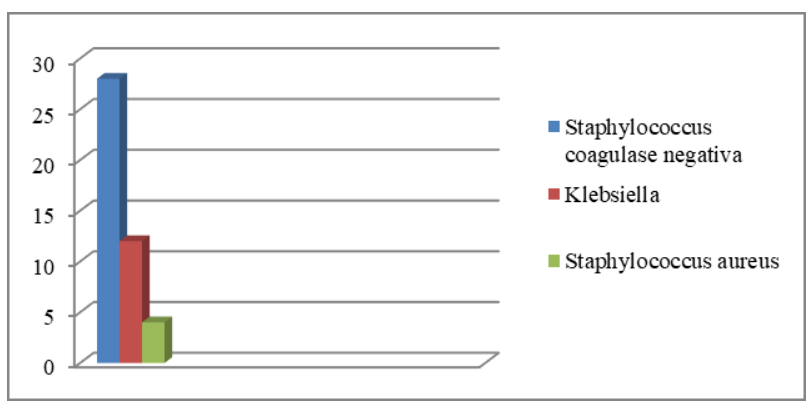

Fonte: Dados da pesquisa, 2018.

Figura 1. Presença e identificação de bactérias em superfície de estetoscópios de alunos do curso de Medicina do UNIPAM

\section{DISCUSSÃO}

O resultado do estudo revelou que $50 \%(n=26)$ dos estetoscópios pesquisados estavam contaminados por microrganismos, índice inferior aos resultados encontrados no estudo de Dutra et $a .^{4}$, em que 96,2\% ( $\mathrm{n}=78$ ) estavam contaminados. A diferença se justifica pelo fato de que no estudo de Dutra et al. ${ }^{4}$ foram incluídos estetoscópios de médicos e enfermeiros, sendo que $79 \%(n=64)$ estavam sob a responsabilidade da enfermagem, e $21 \%(n=17)$ sob a responsabilidade de médicos, enquanto no presente estudo foram avaliados apenas estetoscópios de estudantes de medicina.

O estudo de Xavier e Ueno ${ }^{9}$, realizado em unidade pediátrica, também obteve resultados superiores: $86,8 \%$ $(n=33)$ justificado pelo fato de que médicos realizam menos desinfecção do que internos de medicina, segundo 
questionário aplicado na referida pesquisa.

O número de contaminação no presente estudo foi inferior ao dos dois outros em que os estetoscópios se encontravam em ambientes de UTI's, o que se deve ao fato de os estudantes de medicina do UNIPAM não possuírem contato direto com as unidades.

Em relação às características tintoriais, vale ressaltar que houve a constatação de grande número de bactérias Gram-negativas. O isolamento de microrganismo Gramnegativo representa risco real de propagação de infecções potencialmente graves, o que se deve ao fato de que referidas bactérias, apesar da baixa toxicidade, não são facilmente neutralizadas por antitoxinas ${ }^{3,4}$.

Esse fato contrasta com os achados dos estudos de Neves ${ }^{5}$ e de Sales et al. ${ }^{6}$, visto que ambos os trabalhos encontraram prevalência de germes Gram-positivos. Uma das possíveis razões para essa discrepância de resultados é o fato de que esses estudos foram realizados com jalecos, que ficam em grande contato com a pele, a qual tem uma microbiota composta principalmente por Gram-positivos.

Já Sales et al. ${ }^{2}$, o qual analisou a presença de bactérias nas superfícies inanimadas de uma unidade de terapia intensiva, encontrou também maior prevalência de germes Gram-negativos, que vai em consonância com este estudo.

Em uma unidade hospitalar de Juiz de Fora/MG foram analisados 22 estetoscópios, dos quais 72,7\% apresentou crescimento microbiano. Nessa pesquisa, realizada por Garcia et al. ${ }^{10}$ foram isolados Staphylococcus $s p$ coagulase negativa ( $\mathrm{SCN}$ ), cepas de Acinetobacter baumannii, Enterococcus sp. e Staphylococcus aureus, o que corrobora com a presente pesquisa.

\section{CONCLUSÃO}

Os resultados permitem concluir que a presença de microrganismos patogênicos contaminando a superfície dos estetoscópios analisados pode representar uma fonte de disseminadores de bactérias patogênicas contribuindo para o aumento das IACS.

Nesse sentido, salienta-se que a prática de higienização do diafragma dos estetoscópios deve ser melhor difundida nas instituições de ensino, haja vista que os estudantes estão em constante contato com pacientes, ao passo que o aparelho representa fômite importante de contaminação.

Participação dos autores: Lyza Alencar Siqueira: autora principal. Responsável por idealizar o trabalho, escrever e colher o material e analisá-lo; Liliane Silva Anjos: coautora. Responsável por ajudar a escrever o trabalho e colher o material e analisá-lo; Thainá Pereira do Nascimento: coautora. Responsável por ajudar a escrever o trabalho e colher o material e analisá-lo; Valeska Balen Ronsoni: coautora. Responsável por ajudar a escrever o trabalho e colher o material e analisá-lo; Marilene Rivany Nunes: coorientadora. Responsável por orientar na escrita do trabalho; Ma. Bethânia Cristhine de Araújo: orientadora. Responsável por idealizar, por orientar a coleta e a análise do material e na escrita.

\section{REFERÊNCIAS}

1. Moraes CL, Ribeiro NFG, Costa DM, Furlan VG, Palos MAP, Vasconcelos LSNOL. Contaminação de equipamentos e superfícies de unidades de terapia intensiva de uma maternidade pública por Staphylococcus coagulase negativa. Rev Patol Trop. 2013;42(4):387-94. doi: 10.5216/rpt. v42i4.27927.

2. Sales VM, Oliveira E, Célia R, Gonçalves FR, Melo CC. Análise microbiológica de superfícies inanimadas de uma Unidade de Terapia Intensiva e a segurança do paciente. Rev Enf Ref. 2014;3:45-53. http://dx.doi.org/10.12707/RIII1293.

3. Murray P, Rosenthal KS, Pfaller MA. Microbiologia médica. Rio de Janeiro: Elsevier Brasil; 2015.

4. Dutra LGB, Nascimento Neto HB, Nedel FB, Lobo EA. Prevalência de contaminação bacteriana em estetoscópios. Rev Inst Adolfo Lutz. 2013;72(2):155-60. doi: 10.18241/007398552013721557.

5. Neves JDB. Análise bacteriológica de jalecos de profissionais da saúde de uma clínica escola na cidade de Juazeiro do Norte, Ceará. Rev Interfaces. 2015;3(9):50-4. doi: 10.16891/2317434X.535.

6. Sales WB, Visentin A, Caveião C, Hey AP, Guimarães L, Baptistella RSR. Quantitativo microbiano em jalecos de estudantes da área da saúde em instituição de ensino superior. J Health Sci Inst. 2016;34(4):195-9. Disponível em: https:// www.unip.br/presencial/comunicacao/publicacoes/ics/ edicoes/2016/04_out-dez/V34_n4_2016_p195a199.pdf.

7. Koneman EW. Diagnóstico microbiológico: texto e atlas colorido. 6a ed. Rio de Janeiro: Guanabara Koogan; 2008.

8. Oplustil CP, Zoccoli CM, Tobouti NR, Sinto SI. Procedimentos básicos em microbiologia clínica. $3 \mathrm{a}$ ed. Rio de Janeiro: Sarvier; 2010.

9. Xavier MS, Ueno M. Contaminação bacteriana de estetoscópios das unidades de pediatria em um hospital universitário. Rev Soc Bras Med Trop. 2009;34(2):217. http:// dx.doi.org/10.1590/S0037-86822009000200026.

10. Garcia PG, Damianse LA, De-Oliveira RVT, Da-Silva VM, Calsavara RE. Contaminação microbiana de estetoscópios em duas unidades hospitalares do Estado de Minas Gerais. Rev Med Minas Gerais. 2019;29:e-2008. doi: http://dx.doi. org/10.5935/2238-3182.20190004.

Recebido: 30/10/2019

Aceito: 17/04/2020 